\title{
МИРОВОЙ РЫНОК БАНКОВСКИХ УСЛУГ С ТОЧКИ ЗРЕНИЯ ТЕОРИИ АСИММЕТРИЧНОЙ ИНФОРМАЦИИ
}

\author{
Фомина Марина Валерьевна \\ докт. экон. наук, профессор, \\ зав.кафедрой экономической теории \\ Дещенко Александра Юрьевна \\ канд.экон. наук, \\ доиент кафедры международной экономики \\ Приходько Владимир Викторович \\ ассистент кафедры экономической теории \\ Донеикий национальный университет экономики и торговли \\ имени Михаила Туган-Барановского
}

Аннотация. В сделан вывод относительно того, что рынок банковских услуг по своим параметрам и характеристикам правомерно относить к рынкам с асимметричной информацией, что проявляется: в неравноценном обеспечении активных и пассивных операций банка; различной правовой основе банковских операций; разных механизмах стоимостной оценки взаимных обязательств; асимметричной ликвидности кредитно-денежных операций; наличии интернальных эффектов.

Annotation. The article It is concluded, that the market of banking services on its parameters and characteristics legitimate to refer to the markets with asymmetric information, which manifests itself: in the unequal provision of active and passive operations of the bank; different legal basis of banking operations; different mechanisms for the valuation of mutual obligations; asymmetric liquidity monetary operations; the presence of Internal effects.

Ключевые слова: банковская система, асимметричная информация, дерегламентация финансовых рынков, ликвидность, устойчивость, активные и пассивные банковские операции.

Key words: banking system, asymmetric information, deregulation of financial markets, liquidity, stability, active and passive banking operations.

Актуальность исследования. В последних докладах Международного валютного фонда по итогам функционирования мировой банковской системы красной нитью проходит констатация опасений относительно того, что присущие мировой банковской системе проблемы «too big to fail» (слишком большие, чтобы рухнуть) переросли в проблемы «too weak to service» (слишком слабые, чтобы выжить). При этом подчеркивается, что значительное количество банков самых богатых стран мира, в том числе и треть европейских банков с активами 8,5 трлн. долл. и четверть банков США с активами 3,2 трлн. долл., слишком ослаблены. Им не поможет ни рост экономики, ни повышение процентных ставок. По сути, ставится под сомнение устойчивость, стабильность и эффективность глобальной финансово-банковской системы. Такой пессимистичный вывод свидетельствует о серьезных проблемах и противоречиях, возникших в мировой банковской сфере, и необходимости поиска их первопричин и возможного алгоритма разрешения.

Анализ последних исследований и публикаций. С точки зрения методологии, определенное влияние на формирование представлений о мировой финансово-банковской системе оказали работы классиков экономической теории, связанные с исследованием теорий денег, концепций денежного обращения и основ функционирования финансового и банковского секторов: Рикардо Д., Кейнса Дж.М., Кругмана П., Бернара А. Лиетара, Гринепена А., Халла Джек К.

Но, не смотря на многообразие разработок по данной проблематике, в научных трудах недостаточно исследованными остаются вопросы асимметричности информации и операций в банковском секторе, а также последствия такой асимметричности, ее влияние на стабильность и устойчивость мировой банковской системы.

Целью статьи является исследование специфики функционирования мировой банковской системы с точки зрения теории асимметричной информации для обоснования специфической банковской асимметричности и ее последствий.

Результаты исследования. История становления и развития банковской деятельности имеет довольно запутанный и противоречивый характер. Функционирование банковского сектора не отличается стабильностью и устойчивостью. Например, кризис конца 20-х годов XX века (Великая депрессия) или кризис 2008 г., когда банковская система не только ни стала катализатором кризисных проявлений, а сыграла роль детонатора нестабильности. Не вдаваясь в исторический экскурс, обоснуем базовые аксиомы и посылки настоящего исследования: во-первых, банки и их деятельность методологически вписываются в модель рынка с асимметричной информацией, когда банки и их клиенты как субъекты рыночных отношений владеют неодинаковой информацией и, соответственно, имеют неравнозначные позиции при проведении банковских операций. 
Во-вторых, глубокие и всесторонние трансформации финансового рынка привели к коренным изменениям как роли и функций банков, так и всей сферы банковской деятельности.

В-третьих, на современном финансовом рынке сформировалась новая конфигурация конкуренции, в условиях которой традиционные банки чувствуют себя не всегда «комфортабельно».

В-четвертых, претерпел значительные трансформации общий бренд развития банковской деятельности.

Учитывая вышеизложенное, возникает необходимость скорректировать и уточнить некоторые стереотипные представления и определения банков и банковской деятельности. Традиционно банки рассматриваются как учреждения, функционирующие на финансовом рынке, деятельность которых сводиться к кредитно-депозитным операциям. Подобное определение, с различными тавтологическими интерпретациями, перемещается из учебников в законодательные акты и наоборот. Например, Закон США «О банковских холдингах» определяет банки как институт, который «собирает остатки денежных средств общества, чтобы ссужать их под проценты его коммерческим предприятиям» [1]. Популярный учебник по экономической теории дает другую формулировку, не меняющую сути: «Банки, являются финансовым посредником, который использует ликвидные активы в форме банковских вкладов для финансирования обладающих низкой ликвидностью инвестиций заемщиков» [2, С.780]. Но сегодня таких банков осталось совсем немного, наиболее прибыльные операции большинство из них осуществляют в других сферах, используя совершенно другие инструменты.

Современные банки, по словам известного специалиста в области денег и денежного обращения Бернара А. Листара, «берут свои деньги там, где только могут найти, и используют их для любой разрешенной законом деятельности, которая кажется прибыльной. Они забросили традиционные банковские услуги и включаются в сферу «финансовых» услуг» [3, С.38]. К концу ХХ века «почти 85\% ресурсов банковской отрасли получены из источников, отличных от застрахованных депозитов» [3, С.43]. Речь не идет о том, что банки полностью отказались от традиционной роли «финансовых посредников». Банковские операции, связанные с ней, также имеют место в их деятельности, но они претерпели значительные изменения и не являются доминирующими. Основным объектом кредитования в настоящее время стали не действующие предприятия, а потребители. Хотя история потребительского кредитования начинается с середины XIX века, настоящий его бум начался с 80-х годов XX века, что объясняется рядом объективных факторов: во-первых, переход к неолиберальной экономической модели развития и формирование «общества потребления»; во-вторых, информационно-технологические изменения, связанные с компьютеризацией банковской и торговой деятельности; в-третьих, широкое распространение новых платежных средств (кредитных платежных карт, смарт-карт и т.д.); в-четвертых, развитие новых форм обслуживания денежного обращения (электронная передача денег и др.).

Мировой банковский сектор активно включился в сферу оказания «финансовых услуг» и стал ее субъектом. Первопричиной такого положения стал процесс дерегламентации финансовых рынков, который начался в 80-е года XX века в Англии и США, как базовый при реализации неолиберальной концепции экономического развития.

Поскольку англо-саксонская банковская система является эталонной для мира, исторически процесс дерегламентации целесообразно исследовать на примере США.

Дерегламентация финансовой сферы в США по сути является ответной реакцией на принятие в 1933 г. Закона Гласса-Стигала, который был разработан в рамках системы антикризисных мер по противодействию Великой депрессии, и устанавливал защитную систему банков от финансовых потрясений. В его основу были положены: во-первых, создание федеральной (государственной) корпорации по страхованию депозитов (ФКСД); во-вторых, введение ограничений по степени банковского риска. Таким образом, любой банк, принимающий вклады, лимитировался в выдаче кредитов и их видах; вводились ограничения по кредитным и депозитным процентным ставкам; средства вкладчиков нельзя было использовать для осуществления биржевых операций; запрещалось одному и тому же банковскому учреждению принимать вклады и осуществлять инвестиционную деятельность, т.е. строго разграничивалась традиционная и инвестиционная банковская деятельность.

Борьба банковской элиты против этого Закона была длительной и, в целом, успешной. Основные ее вехи в исторической последовательности можно свести к следующему: во времена Президента Д. Картера был принят Закон о дерегулировании депозитных учреждений и денежно-кредитного контроля, который отменил нормы, запрещающие банкам выплачивать проценты по многим видам вкладов; Президент Р. Рейган в 1982 г. подписал Закон Гарна-Сен-Жермена, ослабляющий ограничение по видам кредитов, которые могли предоставлять банки; пиком дерегламентации можно считать 1986 год, когда Р. Рейган и М.Тетчер убедили станы «большой семерки» (G7) принять основные рыночные принципы финансовой дерегуляции для всех рыночных экономик; заключительная точка была поставлена Президентом Клинтоном, который отменил нормы Закона Гласса-Стигала, разделявшие коммерческие и инвестиционные банки. Последствия этих мер для банков и банковской деятельности имели довольно противоречивый характер и требуют дополнительного тщательного анализа. 
В рамках данного исследования следует обратить внимание на следующие моменты. Рынок банковских услуг по своим параметрам и характеристикам правомерно отнести к рынкам с ассиметричной информацией. Причем, не только в классическом понимании, предполагающем - информационную асимметричность, т.е. субъекты рыночных отношений обладают различной информацией и, соответственно, их поведение определяется ее полнотой и достоверностью, но и определенными проявлениями асимметричности в самой банковской деятельности, что связано со спецификой осуществления банковских операций, назовем ее специфической асимметрией.

Специфическая асимметрия банковской деятельности проявляется в следующем: во-первых, неравновесное и неравнозначное обеспечение активных и пассивных операций банка. Это проявляется в том, что при выдаче кредитов банки используют инструмент залога, и сводят, как правило, риски невозврата кредитов к минимуму. Противоположная ситуация с денежными операциями - вклады обеспечиваются лишь частично, в пределах суммы страховок депозита или объема обязательного частичного резервирования.

Во-вторых, различная правовая основа проводимых банковских операций. Пассивные операции регулируются на основе договоров хранения (депозита или депонирования). Кредитование осуществляется на основе договора займа. Эти документы предусматривают не равнозначную юридическую ответственность.

В-третьих, применение различных механизмов стоимостной оценки взаимных обязательств. Так, активные операции отражаются в банковских балансах по текущей рыночной цене и, гипотетически, существуют риски ее снижения. При этом объем пассивных операций во времени не изменяется, если банк вдруг не стал банкротом.

В-четвертых, асимметричность в степени ликвидности кредитно-денежных операций банка. По пассивным операциям деньги в большинстве случаев могут быть вытребованы в любой момент, т.е. ресурсы для возврата вкладов должны быть высоколиквидными. Что касается возврата кредитов, то он происходит в определенные установленные сроки, т.е. кредитные ресурсы обладают значительно более низкой ликвидностью.

В-пятых, неопределенность и неустойчивость банковской деятельности. Из-за асимметричности информации и асимметричности ответственности при проведении банковских операций появляются интернальные эффекты, представляющие собой выгоды или издержки, которые не проявлялись на момент проведения кредитно-денежных операций.

В конечном счете, все приведенные факты влияют на устойчивость банков, банковской деятельности и финансовой системы в целом.

Побочным эффектом асимметричности банковских операций является проблема, которая в научной литературе получила разные определения: «бегство из банка», «набеги на банк», «наплыв требований» и другие. Поскольку банки, по определению, являются неустойчивой структурой, любая негативная информация о деятельности банка может привести к массовому оттоку вкладов, что, в конечном счете, может привести к панике. Еще Давид Риккардо писал, что «... против теней паники банки не имеют гарантий ни при какой системе. Они подвержены ей по самой своей природе» [4, С. 284].

Деятельность банков базируется на одном достаточно спорном и противоречивом допущении, что все их вкладчики не захотят одновременно изъять свои средства. Но это довольно слабая конструкция, которая в любой момент может быть разрушена не столько стихийно возникающими слухами о финансовых проблемах банка, сколько целенаправленным их генерированием. В этом случае модель рынка с асимметричной информацией действует до наоборот. Один из основоположников теории асимметричной информации Джон Акерлоф считал, что данную проблему можно решить только двумя способами - гарантиями и репутацией. Что касается гарантий, то в случае банковской паники они ограничены установленной нормой обязательного резервирования или страховой суммой. А хорошая репутация возможна только тогда, когда каждый гражданин как потенциальный клиент банка, имеет свободный доступ к информации о финансовом положении банка. Но это невозможно по вышеизложенным причинам и поскольку «деньги любят тишину», а банки всеми возможными способами готовы еe воссоздавать и поддерживать, стараясь действовать непублично, таинственно, ритуально, негласно. Главное сформировать иллюзорное впечатление в незыблемости, монументальности, вечности и стабильности.

Традиционные банки, в итоге проведенных мер по дерегулированию, оказались в довольно жесткой конкурентной ситуации, что обусловлено вполне обоснованными обстоятельствами.

Во-первых, появился новый тип конкуренции в традиционной кредитной среде - конкуренция «процентных ставок». К чему это привело - достаточно точно описал Пол Кругман: «... дерегулирование привело к повышению не столько эффективности, сколько риска. На первый взгляд разрешение банкам конкурировать при помощи ставок по вкладам выгодно для потребителей, однако постепенно это превращало банковское дело в состязание в безрассудстве - выплачивать вкладчикам «конкурентные» проценты мог себе позволить только тот, кто выдавал сомнительные кредиты» [5, С. 98-99]. Аристотель еще в далекой древности отмечал эту «генетическую» черту банковской деятельности: «Все занимающиеся денежными оборотами, стремятся увеличить количество денег до бесконечности» [6, С. 16-17]. Конкуренция «процентных ставок» привела к ситуации, когда, с одной стороны, значительно увеличился риск, а, с другой, банкам стало не хватать 
кредитных ресурсов и одни банки, чтобы выдавать кредиты, стали занимать деньги у других. Все это привело к серьёзным проблемам в банковской сфере.

Во-вторых, расширился спектр конкурентов. Так, втягиваясь в сферу высоко рисковых операций, особенно связанных с производными финансовыми инструментами (ПФИ) или деривативами, банки получили значимых конкурентов в этом сегменте. Речь идет о различных внебанковских финансовых институтах, деятельность которых в основном и была связана с высоко рискованными операциями на финансовом рынке. Поэтому на «своем поле» они чувствовали себя «как рыба в воде» и функционировали достаточно эффективно. Речь идет о страховых компаниях, пенсионных фондах, фондах прямого инвестирования, хедж-фондах, «слепых» и «глухих» трастах и прочих институтах. Одно их перечисление свидетельствует об их бурном развитии, а не следует еще забывать об инвестиционных банках, которые традиционно присутствовали на этом рынке. Следует также отметить, что дерегулирование способствовало выходу на финансовый рынок индивидуальных владельцев денежных средств, получивших возможность проводить финансовые операции без посредников на свой страх и риск.

В-третьих, сформировались альтернативные формы банковской деятельности, так называемый «теневой банковский сектор». В предкризисном 2007 году по некоторым оценкам теневой банковский сектор по объемам операций превысил традиционный [5, С.101]. К этому сектору относятся операции на денежных рынках, которые не предполагают физического присутствия на нем институтов, таких как банковские структуры, проведение операции по выдаче наличных денег, но в остальном работают как текущие чековые счета. Наибольшее распространение получили такие операции как репо, ценные бумаги с опционной ставкой и другие. Данные операции позволяли, как правило, согласовывать интересы заемщиков (получать средства на длительный срок) и инвесторов (иметь оперативный доступ к своим деньгам). Видимая выгода вполне осязаема. Инвесторы, участвующие в этой схеме, получали более высокие проценты, чем по традиционным деньгам, а эмитенты могли привлекать денежные активы по более низким ставкам, чем при банковском кредитовании. Но при проведении подобных операций есть и скрытые цели. Их участники по сути обходили систему регулирования банковской деятельности, которая довольно либеральна, и, соответственно, экономили на затратах на нее. Надо, разумеется, иметь ввиду, что незащищенность данных финансовых инструментов банковской сеткой безопасности, значительно повышает их рискованность.

Современный источник прибыли банков - операции на рынке производных ценных бумаг (ПЦБ), как синонимы часто используются термины «деривативы», «производные финансовые инструменты». Данные о динамике этого сектора финансового рынка, которые приводятся в литературе, довольно противоречивы и не всегда корректны, но этому есть свое объяснение. Этот рынок состоит из двух составляющих: биржевой и внебиржевой. Причем вторая доминирует. И если по биржевому рынку статистическая картина традиционно довольно полная, то статистика внебиржевого рынка носит оценочный характер. Второй момент связан с тем, что, в основном, в статистический чет попадают биржевые продукты (фьючерсы и опционы), даже если они обращаются за пределами биржевого рынка. Другое дело с теми ПЦБ, инициаторами которых являются банки и другие финансовые институты. Например, ценные бумаги с опционной ставкой, которые уже упоминались ранее, схема их оборота, как и они сами, были придуманы «Leman Brothers» в 1984 г., а накануне кризиса 2008 г. вышли на уровень 400 млрд.дол. [7, С. 247]. Самый популярный, среди страховых ПЦБ: Credit Default Swop (CDS, кредитный дефолтный своп). Был изобретен в недрах JP Morgan Chase в середине 90-х годов и отличился в предкризисные годы просто фантастическими темпами роста. В 2004 г. - общий мировой объем сделок CDS приближался к 6 трлн.дол., в 2006 г. - к 20 трлн.дол., в 2008 - к 58 трлн.дол., из них в США - 16,4 трлн.дол. [8, C. 355-356].

Но эти данные приводятся на основе аналитических расчетов и не являются достоверной статистической информацией. Трудность их учета связана также со срочностью проведения операций. Например, соглашение репо действует до конца следующего рабочего дня.

Нельзя также забывать о теневой банковской деятельности с ПЦБ, учет которой, по понятным причинам, значительно затруднен.

Изначально ПЦБ появились, как финансовые инструменты, призванные снизить риск в условиях высокой волатильности цен на биржевые товары, курсов валют и курсов акций. И, в целом, они эту задачу до 80-х годов XX века довольно успешно выполняли. Но, в дальнейшем операции с ПЦБ стали носить чисто спекулятивный характер и, по сути, они стали практически автономны от процессов, протекающих в реальной экономике. Отметим, что ведущую роль в обороте ПЦБ стал играть внебиржевой рынок. Это связано, прежде всего, с тем, что резко увеличился инновационный рост ПЦБ, основу которых составляют далеко не биржевые активы. Приведем косвенный факт такого роста. Хрестоматийная работа Джек К. Халла «Опционы, фьючерсы и другие производные финансовые инструменты», в которой дается развернутая характеристика ПЦБ, в первом издании состояла из 300 стр. (1988 г.), а в шестом - 1072 стр. (2007 г.). По сути дела, сегодня ПЦБ могут создаваться в привязке к любому устойчиво повторяющемуся явлению или процессу, подверженному колебательным, нестабильным изменениям и не всегда, хотя бы косвенно, связанному с экономической жизнедеятельностью. 
Современный бурный рост экзотических опционов, энергетических и страховых ПЦБ, по-видимому, требует уточнения их традиционного классического определения. Так, Д. Халл считает, что ПЦБ - это «финансовый документ, стоимость которого зависит (т.е. является производной величиной) от стоимости других, базовых переменных, ... этими переменными выступают цены разнообразных рыночных активов» [9, C.37]. Целесообразно дополнить определение - переменными выступают и нерыночные явления, и процессы, не всегда имеющие стоимостную оценку или виртуальную цену.

Банки в последнюю четверть века стали одним из основных институтов на рынке ПЦБ. В середине 2016 г. собственный капитал Дойче Банка оценивался в 60 млрд.дол. Соотношение заемных и собственных средств, т.е. долговая нагрузка составляла 40/1. Тогда как номинальный объем риска в операциях с ПЦБ 72,8 трлн.дол., что более чем в 20 раз больше объема ВВП Германии (последний примерно 3,4 трлн.дол.). А его доля в общем объеме ПЦБ составляет около $13 \%$. Не лучше ситуация и у других мировых банковских лидеров: НСВС, JP Morgan, Bank of America, Goldman Sachs. Поэтому положение банковской системы зависит от состояния этого рынка. Кризис 2008 г. затронул рынок ПЦБ незначительно, только в той его части, где рыночным активом являлись закладные по ипотечным кредитам.

Исходя из сказанного, правомерно сделать констатировать, что в последнее время усилилась асимметричность банковских операций, что, в конечном счете, способствовало повышению неустойчивости банков и банковской системы в целом. Деятельность современных банков по извлечению прибыли все больше связана с высоко рискованными финансовыми инструментами, потому прогнозировать их будущее довольно сложно и бесперспективно. Следует обратить внимание на следующее обстоятельство. Обязательства и распределение рисков по операциям с ПЦБ имеет двойственный характер. С одной стороны, они своеобразно цементируют и укрепляют банковскую систему, а, с другой, деформация или разрушение одного звена в этой «круговой поруке» может вызвать непредвиденные последствия, по сравнению с которыми кризис 2008 г. будет выглядеть как небольшое недоразумение. Пророчески сегодня воспринимается высказывание Дж. М. Кейнса, что «спекулянты могут и не причинить никакого вреда, как пузыри на устойчивом потоке предпринимательства. Но положение осложняется, когда предпринимательство само становиться пузырем в водовороте спекуляции. Когда экономическое развитие страны становится побочным атрибутом деятельности казино, работа, вероятно, была плохо выполнена [10, С. 139].

Выводы. На основе исследования сделаны следующие теоретические обобщения и выводы:

1 - Аксиоматика исследования базируется на посылках: банки и их деятельность методологически вписываются в модель рынка с асимметричной информацией; трансформации финансового рынка привели к коренным изменениям как роли и функций банков, так и всей сферы банковской деятельности; на современном финансовом рынке сформировалась новая конфигурация конкуренции, в условиях которой традиционные банки чувствуют себя не всегда «комфортабельно»; претерпел значительные трансформации общий бренд развития банковской деятельности.

2 - Изменения в специфике банковской деятельности связано с действием ряда объективных факторов: переход к неолиберальной экономической модели развития и формирование «общества потребления»; информационно-технологические изменения, связанные с компьютеризацией банковской и торговой деятельности; широкое распространение новых платежных средств; развитие новых форм обслуживания денежного обращения.

3 - Исторически процесс дерегламентации финансово-банковской сферы - это борьба за отмену Закона Гласса-Стигала, жестко регламентирующего банковскую деятельность и переход к неолиберальной концепции экономического развития.

4 - Рынок банковских услуг не только целесообразно относить к рынкам с асимметричной информацией, но необходимо выделять как отдельное понятие - специфическую асимметричность банковских операций.

5 - Специфическая асимметричность банковского сектора проявляется в следующем: неравновесное и неравнозначное обеспечение активных и пассивных операций банка; различная правовая основа проводимых банковских операций; применение различных механизмов стоимостной оценки взаимных обязательств; асимметричность в степени ликвидности кредитно-денежных операций банка; неопределенность и неустойчивость банковской деятельности.

6 - Последствия процесса дерегламентации финансово-банковской сферы для мировой банковской системы выразились в следующем: появился новый тип конкуренции в традиционной кредитной среде конкуренция «процентных ставок»; расширился спектр конкурентов; сформировались альтернативные формы банковской деятельности, так называемый «теневой банковский сектор».

\section{СПИСОК ЛИТЕРАТУРЫ:}

1. Банки и банковская система США. Электр. pec. Режим доступа: hhtps//state-usa.ru/system/219-banki-ibankovskaya system. 
2. Кругман П. Основы экономикс: учебник для вузов / П. Кругман, Р. Веллс, М. Олни // пер. с англ. - СПб: Питер, 2012 - 880c.

3. Бернар А. Лиетар. Будущее денег: новый путь к богатству, полноценному труду и более мудрому миру / Бернар А. Лиетар - М.: КРЛА Олимп, 2007. - 493с.

4. Рикардо Д. Начало политической экономии и налогообложение /Д. Рикардо // Соч. Т.1. - М.: Госполитиздат, 1956. - 360с.

5. Кругман П. Выход из кризиса есть! /П. Кругман // Пер. с англ. Ю. Гольдберга. - М.: Азбука-Бизнес, 2013. $-333 \mathrm{c}$.

6. История экономических учений [учебник] / Под ред. В. Автономова. - М.: ИНФРА - М, 2010. - 784c.

7. Кругман П. Возвращение Великой депрессии / П. Кругман.// Пер. с англ. В. Егорова. - М.: Эксимо, 2009. - $336 \mathrm{c}$.

8. Гринепен А. Эпоха потрясений / Проблемы и перспективы мировой финансовой системы. // Пер. с анг. - М.: Юнайден Пресс, 2010. - 550 с.

9. Халл Джек К. Опционы, фьючерсы и другие производные финансовые инструменты. / Джек К. Халл. // Пер.с англ. 6-е изд. - М.: ООО «И.Д. Вильямс» - 2007. - 1072 с.

10. Кейнс Дж.М. Общая теория занятости, процента и денег. Избранное /Дж.М. Кейнс. - М.: Эксимо, 2007. $-960 \mathrm{c}$. 